\title{
Participatory Economy and Overtourism: The Long-Term Effect on the Economic Dynamics of Fort-Kochi
}

\author{
FAZLUR RAHMAN*1; NORHAZLIZA ABD HALIM² \\ ${ }^{1} \mathrm{PhD}$. Research, Urban and Regional Planning, Faculty of Built Environment and Surveying, UNIVERSITY \\ TECHNOLOGY MALAYSIA (UTM), MALAYSIA; E-mail: arfazlur121@gmail.com \\ ${ }^{2}$ Centre for Innovative Planning and Design, Tourism Planning Research Group, UNIVERSITI TEKNOLOGI \\ MALAYSIA (UTM), MALAYSIA; E-mail: norhaz@utm.my
}

\begin{abstract}
Over the two decades Kochi, Kerala has experienced remarkable growth in a number of tourists, both domestic and international tourists increased to more than 30 percent between 1996-2016. The aim of this paper is to evaluate the long-term impact of participation and overtourism on the market dynamics of Fort-Kochi, as it became a popular tourist destination for their heritage values with a unique geographical location. Fort-Kochi located in the North-Western part of Kerala State in Kochi district is the main heritage tourist's attraction. It is known for its natural and built heritage, and become a great attraction for international tourists who find the experience both of exotic and heritage. Being more popular and being loved too much will become a challenge and which leads to overtourism. This research is trying to elaborate on the trend of mass-tourism and its impact on the economy of Fort-Kochi, as noticed a significant change in trends of tourist's shopping. It is brought out the economic problem of inflation and displacement of traditional occupation due to the uncontrolled increases of tourism activities in the Fort-Kochi. Due to overtourism and impact of factory-made market leading to endangering line on traditional craftsmanship. It is being threatened with extinction, and the consequences will be catastrophic. It is projected that such a trend may have a significant impact upon the local population of FortKochi. This study is based on a survey of 25 local resident's feedback, 50 shop-owners and craftsmen and 50 tourists about the trend of shopping, demand and supply and its impact on city dynamics.
\end{abstract}

Keywords: Economy Dissolution, Participation, Overtourism, Fort-Kochi, Economic-regeneration.

JEL Classification: Z 


\section{Introduction}

Kochi (Cochin), known as the Queen of the Arabian Sea, due to its notable importance in the world map for travellers and traders over the centuries (1). Fort-Kochi is an elegant region situated at the west of the Kochi city. It is famous for its culture and heritage tourism (2). Fort-Kochi has always been famous for its global outlook. For its historical importance, it is famous for heritage, culture, and architecture (3). Fort-Kochi is well known all over the world for its spice, tea, cashew nuts, coconuts, coir products, and handicrafts (4). The international trade relationship and development of cultural heritage tourism has a great impact on the culture and heritage aspects of Kochi's social structure.

Tourism plays an important role in the economy of Kerala. For the overseas and domestic tourism market, Kerala state is considered as one of the most sustainable tourism destinations in the east by Kerala Tourism (5). Fort-Kochi is the prime centre for Kerala tourism. For Fort-Kochi, tourism generates 13.04 percent of the State's GDP. As Fort-Kochi capitalizes on their environmental advantages, it is also promoting its unique cultural and built heritage tourism. Their products and approaches to tourism development are very different. It promotes heterogeneous tourism development with natural built heritage and cultural values with upscale and inexpensive charter tourism to both domestic and overseas tourists. The experience in Kerala tourism, especially in Fort-Kochi, varies in terms of their social conflict, environmental impacts, and socio-economic response. After revising the experience and effects of traditional markets on long-term for Fort-Kochi, there is much that can be learned and should be considered for the long-term impact of overtourism.

Overtourism is the concept of the rise of anti-tourism sentiment among the host community $(6,7)$. As a rise in the number of tourists according to tourist statistics of Kerala for the last fifteen years, it leads to mass-tourism, especially in Fort-Kochi. It is overloaded by the visitors and its impacts are being noticed in many sectors. Nowadays, Fort-Kochi undergoes a significant change in the evolution of global tourism, which leads to overtourism. It comes in existence when every nation of the world is trying to grow their paw into a big claw in such a booming industry. The rise in anti-tourism sentiment is "a very serious situation that needs to be addressed in a serious way" (8). Due to overtourism in Fort-Kochi and its long-term impact of readymade market leading to endangering line on traditional craftsmanship. It is being threatened with extinction, and the consequences will be catastrophic. The change in the trend of shopping in such a tourism industry is taking place, which leads to the economic decline of the traditional market of Fort-Kochi.

\section{Objective of Study}

Objective of this study is to know the trend of sustainable tourism and its growth and assess the impact of factory-made products on the dynamics of socio-economy of Fort-Kochi. Data sources of this study are both primary and secondary.

\section{Literature Review and Research Gap}

Being an Island city, Fort-Kochi has a very unique Environmental, Heritage and Cultural features, which promote this city's ever-growing demand for tourism and trade over the centuries (9). According to geographical location, the Fort-Kochi placed right at the sea mouth and has experienced immense trade-related activities and has developed a rich pluralistic culture and tradition unique to this heritage zone (1). For the development of tourism business and making provision for attraction to the tourists, local communities play an important role in rising of the local economy. However, on the engagement of people from the local community requires a different approach to the business sense of creating a sustainable economy (10).

The historical evolution of Kerala, Kochi as a part, was unexplored until the exploration of Portuguese in the late fifteenth century $(11,12)$. In mid-twenty century, city of Kochi grew around Ernakulum as a major town. Due to its heritage-related issues, Fort-Kochi had been left behind by the developments and investments. However, in the late 20th century, as growing demand for the tourism 
industry in Kerala has made this heritage zone alive again (1). In early 21st century, this city was being much popular among tourists both domestic and overseas. As a result of overtourism Fort-Kochi has been experiencing with few remarkable issues. Overtrading, uncontrolled development, and environmental issues are being notified (1). Pulling down an uncontrolled modification of traditional market is becoming a major issue in Fort-Kochi (13). Modification in the nature of traditional market and its trends and alien external influence of factory-made cheap products and its consumption is destroying the harmony of Socio-economy of this heritage city. As intense use of factory-made products and continuous introduction of such cheap products affects the craftsmanship and local economy.

As Travel and tourism account the $10.20 \%$ of the world's GDP, i.e. \$7.6 trillion (14) and 01 out of 10 jobs on this planet related to the tourism industry, it is easy to understand why every nation wants to be a part of this industry, especially in increasing the number of tourists. What will happen when it became too many foreign influences into the local values? Every part of the world will become Venice as 60,000 people visited every day against 55,000 of their native population (approx. 30million visitors annually against 55,000 local dwellers) (15). The floating population will become more than its original population, which leads to affects the quality of life of dwellers as they come in the mainstream of bargaining (6).

Due to the passage of time, built heritage of Fort-Kochi left the form as a trace of past (16). The Portuguese, the Dutch, French and the English came to Kochi and added a new chapter to the rich history of this land (17). Fort-Kochi is famously known for St. Francis Church, built by Portuguese in 1503, which is a 1st European Catholic Church in India. It is known for the grave of a famous traveller "Vasco da Gama" as he was initially buried. Today's spreading of working in Kochi sends back huge remittances, which play a significant part in sustaining Fort-Kochi's economy and feed its high-cost high wage structure. Kochi is the second most important port city on the western coast of India and is the commercial capital of Kerala and is situated in Ernakulum District, located in the central region of the State, between the Western Ghats and the Arabian Sea.

\section{Methodology}

In this research cultural heritage tourism in the Fort-Kochi and impacts of overtourism on the local market are presented. A questionnaire was designed for this research and focuses on various aspects of the economy of the study area. Moreover, various literature was also used to develop the gap. Effectively 125 samples were surveyed. 25 local dwellers, 50 shop-owners, 25 domestic and 25 international tourists were approached. Data were gathered in November 2017, which is a peak tourist season in Kerala (Oct - Feb). Most of the questions are based on 5-point Likert's scale, and the questionnaire was pilot tested (based on economic dynamics). Means and values deviations are the descriptive statistics used in the explanation of the responses gathered during the research. Results were tested to determine whether there was a significant difference between perceptions of the respondents, and item mean score. The questionnaire was distributed among the local dwellers, shopkeepers and recorded for a couple of weeks. Besides the questionnaire, semi-structured interviews with shop-owners and tourists were conducted to verify the survey results.

Tourism of Kerala is concentrated on natural and built heritage especially in Kochi, where over $80 \%$ of domestic and about $98 \%$ of the international tourists (part of total international tourists visited in Kerala) are frequent in Fort-Kochi region (18), which demonstrates itself the importance of this region in Kerala tourism. Fort-Kochi is visited by two types of tourist with very distinct needs. The first is domestic tourist, who comprises $93.2 \%$ of all tourists. These people come in search of the culture and heritage that is very different from the rest of India, as the intangible cultural heritage of Kerala. The second is the overseas, who visited Kochi mainly for the natural and built heritage of Kerala (19). 
Table 01: Survey brief

\begin{tabular}{|c|c|}
\hline \multicolumn{2}{|c}{ Table 01: Survey brief } \\
\hline Target sample & Tourists aged 18 and above \\
\hline Sample unit & Individual survey \\
\hline Location & Fort-Kochi, Kerala \\
\hline Methodology & Face-to-face interview with a structured questionnaire \\
\hline Sample size & $125(130$ valid interviews) \\
\hline Sampling error & $\pm 3.50 \%$ (consideration) \\
\hline Significant level & $95 \%$ as $(i=0.5)$ \\
\hline Survey time & November 2017. \\
\hline
\end{tabular}

\section{Nature and Growth of Tourism:}

The timing of visits is clearly different for overseas and domestic tourists. In previous decades, a clear offseason for all tourists could be seen, as domestic tourists visited throughout the year, while international tourist avoids the monsoon months, as rainfall is very high, caused trouble in exploration to the visitors in Kerala. On analysis of tourist statistics of Kerala, concluded that domestic tourism for Kerala is comparatively high as international tourist.

Table 02: Share of Domestic and International Tourist of Kerala

\begin{tabular}{|c|c|c|c|}
\hline Year & Total Tourists & $\begin{array}{c}\text { Share of Domestic } \\
\text { Tourist (\%) }\end{array}$ & $\begin{array}{c}\text { Share of International } \\
\text { Tourist (\%) }\end{array}$ \\
\hline 2003 & 6165849 & 95.2 & 4.8 \\
\hline 2004 & 6317728 & 94.5 & 5.5 \\
\hline 2005 & 6292922 & 94.4 & 5.6 \\
\hline 2006 & 6700258 & 93.6 & 6.4 \\
\hline 2007 & 7158749 & 92.8 & 7.2 \\
\hline 2008 & 8190179 & 92.7 & 7.3 \\
\hline 2009 & 8470795 & 93.4 & 6.6 \\
\hline 2010 & 9254340 & 92.9 & 7.1 \\
\hline 2011 & 10114440 & 92.7 & 7.3 \\
\hline 2012 & 10870550 & 92.7 & 7.3 \\
\hline 2013 & 11715954 & 92.6 & 7.4 \\
\hline 2014 & 12618777 & 92.6 & 7.4 \\
\hline 2015 & 13443050 & 92.7 & 7.3 \\
\hline 2016 & 14210954 & 92.7 & 7.3 \\
\hline 2017 & 15765390 & 93 & 7 \\
\hline
\end{tabular}

Source: synthesis data, (18) Gov. of India.

Table 02, shows the statistics of Domestic and International tourists for the last fifteen years. The massive tourist visiting Kerala are Domestic, and the progressive trend has risen considerably in the last fifteen years. A rise in the share of international tourists has been recorded as compared to Domestic tourists, however, the majority of visitors are Domestic.

According to official report of KTDC, Department of Tourism, and Kerala Tourist Statistics, during the period of 1991-1996 an increase in domestic tourist and international tourists was monitored, the period of 1996-2001, saw a bit slow in growth for domestic and international tourist numbers, and during 2001-2006 slower down the growth of domestic tourists, while a moderate rise in international 
tourists were recorded, however in last decades from 2007-2017, a rise in domestic tourist and sharp increase in international tourists are recorded.

Table 03: Average annual growth rate of Tourist in Fort-Kochi:

\begin{tabular}{|c|c|c|c|c|}
\hline \multirow{2}{*}{ Year } & \multicolumn{4}{|c|}{ Annual Growth Rate } \\
\cline { 2 - 5 } & No. & $\%$ & No. & International Tourist \\
\hline 2013 & 163050 & 9.7 & 101744 & 16 \\
\hline 2014 & 212263 & 30.2 & 115013 & 13 \\
\hline 2015 & 197257 & -7.1 & 128975 & 12.1 \\
\hline 2016 & 185694 & -5.8 & 118574 & -8 \\
\hline 2017 & 202535 & 9.1 & 102362 & -13.6 \\
\hline
\end{tabular}

Source: synthesis data, Tourist Statistics of Kerala, Ministry of Tourism, Gov. of India

Table 03, shows the tourist progression in Fort-Kochi region. Rise of tourist footfall increases gradually in Kerala. For 2016 statistics, it shows an increase of International tourists by $6.23 \%$, and an increase of domestic tourists by $5.67 \%$ over the previous year for Kerala (Kerala tourist statistics-2016), however, in Fort-Kochi, it is reduced accordingly.

There are various factors that have contributed to such a rise in domestic tourist over overseas are-

- Increase urbanisation and stress of living in urban areas.

- Increase disposable income for the middle class and upper middle class.

- Increase short term benefits.

- Development of mass transports, increase the number of ferries and increase the number of trips.

- Increase in consumption of factory-made items, which is diluting the traditional market.

- Lack of promotion of Fort-Kochi within the promotion of Kerala Tourism.

\section{Impact of Overtourism in Fort-Kochi:}

The challenge of managing tourism sustainably for tourists, day visitors, and residents has been recognised for Kochi. However, the dominant paradigm has been of tourism in Fort-Kochi as a mainly unquestioned in a better way with sustainable and sustainability liberally applied to reassure the adversely impacted industry of this area. In the last five years, there has been a radical change in tourism, and has a prominent impact of mass-tourism for Fort-Kochi. As a result of overtourism, increases the stress on dwellers for sustainability, increases the stress on aquatic life (as increase in numbers of ferries and trips for facilitating the transport to tourists visits to Fort-Kochi). Due to over demand, increases the trend of short-term benefits among shopkeepers. It hampers the craftsmanship, as handmade products are replacing by factory-made cheap items, which reduces the originality and reliability of the souvenir products. Overexploitation of traditional market leads the competitive market for local dwellers. It has many transitional aspects on the economy of Fort-Kochi.

\section{Economic Aspects of Tourism in Fort-Kochi:}

Table 04, Shows the distribution and trends of expenditures for domestic and international tourists, visited to Fort-Kochi region. It helps to understand the trends of economy generation and the extent of demand by the visitors to this region. 
Table 04: Distribution of expenditures for domestic and International tourists:

\begin{tabular}{|c|c|c|c|}
\hline S. No. & Categories & Domestic tourist (\%) & International tourist (\%) \\
\hline 1 & Shopping & 48.2 & 51 \\
\hline 2 & Food & 16.5 & 14 \\
\hline 3 & Entertainments & 22.8 & 25.5 \\
\hline 4 & Internal transports & 3 & 1.5 \\
\hline 5 & Avg. length of stay & 5.5 & 7 \\
\hline 6 & Miscellaneous expenses & 4 & 1 \\
\hline & Total & 100 & 100 \\
\hline
\end{tabular}

Source: synthesis data, Academic Report-Urban Studio-Urban Development of Kochi, chapter-Tourism, 2015

The economy of Fort-Kochi is transmitted mainly on the tourism activities, performed by the visitors of Fort-Kochi. It is moreover related to types of tourist's nature and scopes of shopping activities. Shopping in Fort-Kochi is mostly depending on traditional markets, which consists of souvenirs of Kerala. It depicts the heritage, culture, and tradition of the state through art, and architecture of the place. Therefore, economic activities of Fort-Kochi are directly proportional to the influx of tourists, both domestic and overseas. Table 03, clearly demonstrates the flow of the economy, majorly on shopping and entertainment activities, which are equally participated by both domestic and international tourist, visited Fort-Kochi.

\section{Surveys and Findings:}

\subsection{Surveys:}

Surveys were carried on 125 respondents effectively at Fort-Kochi, in November 2017, and it was performed for a couple of weeks to get appropriate information from the respondents. Table 05 , shows the types of respondents categorised in different groups. Every group has been asked for different aspects of the economy of Fort-Kochi. The Questionnaire was designed in such a way that, can cover the dynamics of the economy of such a versatile trail of tourism.

Table 05: Types of Respondents under study

\begin{tabular}{|c|c|c|}
\hline Group & Category & Number of respondents \\
\hline Group-I & Local Residents in Fort-Kochi & 25 \\
\hline Group-II & Shop owners & 50 \\
\hline Group-III & Domestic Tourists arrived in Fort-Kochi & 25 \\
\hline Group-IV & Foreign Tourists arrived in Fort-Kochi & 25 \\
\hline
\end{tabular}

Table06: Impact of Factory-made products on Traditional Local Market

\begin{tabular}{|c|c|c|c|c|c|}
\hline \multirow{2}{*}{ Category } & \multicolumn{5}{|c|}{ Response in (\%) } \\
\cline { 2 - 6 } & Very High & High & Moderate & Less & Negligible \\
\hline Market Places & 15 & 76 & 8 & 1 & \\
\hline Price & 82 & 15 & 3 & & \\
\hline Local shopping Area & 20 & 68 & 8 & 4 & \\
\hline Sea food Farming & 15 & 60 & 12 & 8 & 4 \\
\hline Pollution generation & & 36 & 45 & 15 & \\
\hline Exploitation of In-house industry & 10 & 82 & 7 & 1 & \\
\hline Jobs for Local dwellers & 55 & 40 & 5 & & \\
\hline Local migration & 15 & 68 & 10 & 6 & 1 \\
\hline
\end{tabular}

Source: self-survey, 2017 
Table 06 was carried on group-I, 25 local residents of Fort-Kochi. It shows the direct and indirect impact of the local community. Most of the respondents are strongly agreed with the impact of factorymade products on their livelihood. It has a negative impact on the nature of shopping and hampers the trend of traditional shopping activities. It shows the high impact on jobs of local community dwellers, and direct impact on the price of the locally available products which are consumed by the local residents.

Table 07: Impact of ready-made products on Traditional Shopping market

\begin{tabular}{|c|c|c|c|}
\hline \multirow{2}{*}{ Category } & \multicolumn{3}{|c|}{ Response in Average (\%) } \\
\cline { 2 - 4 } & more & moderate & less \\
\hline Price & 4 & 30 & 66 \\
\hline Availability & 38 & 61 & 1 \\
\hline Demand & 12 & 88 & 78 \\
\hline Quality & 2 & 20 & 92 \\
\hline Variant (options) & 55 & 45 & 76 \\
\hline Craftsmanship & & 8 & $\Sigma=44.71$ \\
\hline Jobs & & 24 & \\
\hline
\end{tabular}

Source: self-survey, 2017

Table 07 was carried on group-II, 50 shop-owners in Fort-Kochi. It is based on the perceptions of shop-owners. It shows the direct impact of ready-made products on the traditional market, which reduces the trends of shopping for visitors. It has a negative impact on the traditional market, results of dilution of economy, which is generated from the visitors.

Table 08: Demands of products by tourists (major consumable items)

\begin{tabular}{|c|c|c|c|c|c|c|}
\hline \multirow{2}{*}{ Types } & \multicolumn{6}{|c|}{ Response in average (\%) } \\
\cline { 2 - 8 } & \multicolumn{3}{|c|}{ Domestic tourist } & \multicolumn{3}{c|}{ International tourist } \\
\cline { 2 - 8 } & More & moderate & less & More & Moderate & less \\
\hline Souvenir & & 30 & 70 & 5 & 40 & 55 \\
\hline Handcrafts & 2 & 28 & 76 & 4 & 45 & 51 \\
\hline cosmetics & & 45 & 55 & 1 & 20 & 79 \\
\hline Food items & 5 & 60 & 35 & & 55 & 45 \\
\hline Handlooms & 1 & 7 & 92 & 8 & 59 & 33 \\
\hline
\end{tabular}

Source: self-survey, 2017

Table 08 was carried on group-III and IV, 25-domestic tourist and 25-international tourist, visited Fort-Kochi. It is based on the level of interest of visitors at Fort-Kochi. It shows the fall of demands of tourists, both domestic and overseas were recorded, major fall in demand of domestic tourists while the demand for international tourists was comparatively less. Due to the dilution of factory-made alienated products in the mainstream of tourism trade, which affects the overall demands of the tourists and as a result, degradation of craftsmanship was recorded in Fort-Kochi.

\subsection{Findings:}

To evaluate the cause of fall of tourists, both in domestic and international, and socio-economic depletions, and long-term impacts on the local economy of Fort Kochi, a survey was carried. Through this survey, it was concluded that, due to adulteration in products, majorly, demands of traditional products were reduced, whereas craftsmanship was affected directly. On survey analysis, the following findings were recorded- 
- Lack of proper supply chain (fulfil the demand as rises with a rise in tourist numbers per year)

- Adulteration of products in the traditional market.

- Reduction of working capital for the artisans/NGOs.

- Lack of efficient entrepreneurship development (due to economic degradation in such traditional market)

- Lack of awareness about technology to be implemented in the process of design change.

- Inadequate marketing facilities/ handholding supports for forward and backward linkages.

- Approval of uncontrolled supply of factory-made cheap items, which dilutes the nature of the traditional market.

- Dilution of the economy of Fort-Kochi (both shop-owners and local residents are affected)

- Reduction of tourist influx, both in domestic and overseas were recorded (tourist statistics for Fort-Kochi), which may cause from the reduction of the interest of tourists and negotiation in traditional shopping trends, due to overconsumption of factory-made alienated products at lower price and quality.

\section{Suggestions:}

A major impetus for the heritage tourism of Fort-Kochi initiatives came when links were established to the development programme for such heritage-rich tourism sector. On the basis of findings and issues, eradication of Market Dilution through facilitation and development of entrepreneurial skills amongst local population of Fort-Kochi and craftsmen, while contributing to local economic development through programme "skill development programme" is a strong initiative for the FortKochi region. Under "make in India" programme, the cultural-heritage tourism of Fort-Kochi held the potential for opening up markets for traditional goods and services that in turn could be a spur for the local entrepreneurship development and thereby eradication of economy dilution. For fall in price, an acceptable price needed to be negotiated. In some instance, locally produced items could be more expensive with price lower outside the locality. It requires quality control of traditional items produced could be of prime importance.

Other initiatives that were also promoted under the economic development module, where initiative could be done through development of microenterprises in souvenir units, the formation and promotion of art and culture, development of environmental protection initiatives, such as the introduction of eco-bags instead of plastic bags, etc. Further at ground level, economic revision needed through the generation of multifaceted resources mapping (containing information on different kinds of resources of economy generation and its control for overuse), and a labour directory were maintained to help with planning department (Department of Tourism, Government of Kerala, India). Corporate Social Responsibility can be defined as 'actions that appear to further some social good, beyond the interests of the firm and that which is required by law' (20). As (21) suggests a pyramid of corporate social responsibility, wherein suggests that, while economic sustainability is a fundamental motive, other motivations can also feed into it through enhancing the corporate social responsibility for Kerala region (22), (23).

The government, local bodies (like HDCK, KTDC, KADCO, KITTS) whose role has to be changed as a facilitator rather than a provider, should intensify its interventions in creating adequate infrastructures, creating appropriate environment to attract private investor, technical upgradation, diversifications and modernization for the regeneration and strengthening the local economy sector of Fort-Kochi. Local governing bodies should make a provision to control the adulteration of the market in avoidance of consumption and promotion of factory-made cheap products in such heritage-rich tourism-industry based market, therefore government need to promote the handcrafts products with tourism promotion of Kerala. 


\section{Research Outcomes:}

Kerala is famous for its natural and built culture, it is known as one of the Ten Paradise on earth. Fort-Kochi is the prime centre for the tourism industry in Kerala, therefor regeneration of the economy of Fort-Kochi and evolution control of market paradigm shift is needed. In the end, following research outcomes are identified:

- Fort-Kochi delivers a world-class, yet local visitor experiences.

- Tourist sector attracts investment, which will be sensitive to the traditional market of FortKochi.

- Community gets direct benefits from the tourism

- It will help to create an enabling environment for investors.

- Helps to identify the cause of the fall of the local economy and make provision to eradicate the traditional market dilution.

\section{References}

1. Josna RP, Kasthurba AK. Symbiosis of Conservation and Development: Historic City of Kochi, Kerala, India. International Conference on Transport, Civil, Architecture and Environment engineering (ICTCAEE'2012) 26-27 December 2012; Dubai (UAE)2012.

2. Menon CA. The Cochin State Manual. S. R, editor. Thiruvananthapuram: State Editor, Kerala Gazetteers Department; 1995.

3. Bejoy J, Ramaraj K. Impacts of Sustainable Cultural Tourism in Fort Kochi, Kerala. Shanlax International Journal of Arts, Science \& Humanities. 2015;3(1):109-15.

4. Arackal M, Kurisinkal F. Exploring Cochin. In: Arackal M, editor. 1. Kochi: Vasco Da Gama Research Institute of Cochin; 2008.

5. Francois JR. Tourism in Kerala - a role model? In: Thimm T., W. F, editors. Indien-Tourismus. Germany2011. p. 137-60.

6. Alexis P. Over-Tourism and Anti-Tourist Sentiment: An Exploratory Analysis and Discussion. Ovidius University Annals, Economic Sciences Series. 2017;XVII(2):288-93.

7. Greenberg P. The Growing Problem of Overtourism. Travel and Events2018.

8. Francis J. Crowded Out: The Story of Overtourism. The Guardian. 201816 July.

9. Menon S. At the Margins of Postcoloniality: Kochi as an Imagined City. Media and Cultural Studies. 2016(1):9.

10.Bobbin J, Goodwin H. The Local impacts of coconut Lagoon in Kumarakom. Responsible Tourism Partnership. 2018;3(1):13.

11.Krishnan TV. Mathrubhumi. E.Print, Malabar (Mal.) ed. Krishnan TV, editor1985.

12. Menon AS. Cultural Heritage of Kerala. Menon AS, editor. Kottayam, Kerala: D C Books; 2010.

13.Oommen MA. Micro Finance and Poverty Alleviation: The Case of Kerala's Kudumbashree. Centre for Socio-economic \& Environmental Studies. 2008:17.

14.Greenberg P. World Economy Report. Switzerland, 2018; 2018 February 2018.

15.UNWTO-globaldit, idt. Global Report on Inclusive Tourism Destinations Model and success stories. Middle east; 201818 oct 2018.

16.Isaac TM, Franke RW. Local Democracy and Development: The Kerala People's Campaign for Decentralized Planning: Rowman \& Littlefield Publishers; 2002. 264 p.

17.Corporation of Cochin. Cochi- The City of Heritage. Cochin: Centre of Heritage, Environment and Development; 20132013.

18.Tourism Statistics-Ministry of Tourism GoK. Kerala Tourism Statistics. In: Tourism RaSDDo, editor. Thiruvananthapuram, Kerala, India: Research and Statistics Division Department of Tourism, Government of Kerala; 2003-2017. 
19.Tourism statistics of Kerala. Kerala Tourism Statistics. In: Department of Tourism GOK, editor. Park View, Thiruvananthapuram, Kerala, India: Research \& Statistics Division Directorate of Tourism; 2016-17.

20.McWilliams A, Siegel D. Corporate social responsibility: A theory of the firm perspective. Academy of management review. 2001;26(1):117-27.

21.Carroll A. The Pyramid of Corporate Social Responsibility: Toward the Moral Management of Organizational Stakeholders. Business Horizons. 1991;34:39-48.Chettiparamb A, Kokkranikal J. Responsible tourism and sustainability: the case of Kumarakom in Kerala, India. Journal of Policy Research in Tourism, Leisure and Events. 2012;4(3):302-26.

22.Khan, Nohman, and Muhammad Qureshi. "A systematic literature review on online medical services in Malaysia." (2020): 107-118. 